\title{
Frequency converter for induction heating oil in oil pipelines
}

\author{
N.T ISEMBERGENOV \\ Gumarbek Daukeev Almaty University of Energy and Communications, \\ Almaty, Kazakhstan \\ A.J.SAGYNDIKOVA \\ Gumarbek Daukeev Almaty University of Energy and Communications, \\ Almaty, Kazakhstan \\ M.ZH.KONYROVA \\ Gumarbek Daukeev Almaty University of Energy and Communications, \\ Almaty, Kazakhstan
}

\begin{abstract}
Heating oil in oil pipelines to the required temperature, with the most efficient use of electrical energy,is possible with using of the induction heating method. The most important parameter of induction heating settings is frequency. For each process, there is an optimal frequency range that provides the best technological and economic results. Induction heating of the oil pipeline occurs as follows, if alternating high-frequency current is passed through the windings of the oil pipeline inductor (Fig. 1), an alternating magnetic field is formed, which intersects the metal walls of the oil pipeline and induces eddy currents in them. These currents heat the metal walls of the pipeline to the desired temperature and, accordingly, the oil. MITSUBISHI's VIPM Series Intelligent Power Transistor Modules (IPM), which is a functionally complete product, are currently developed and marketed. These transistor modules are designed for high voltages, currents and power. A frequency converter made on these transistor modules allows to heat large diameter oil pipelines.

A prototype IGBT transformer was designed and manufactured. Figure 2 shows a prototype of a frequency converter with a power of $6 \mathrm{~kW}$ at frequencies from 2 to $20 \mathrm{kHz}$. Induction heating of metal was used as a load for the frequency converter.
\end{abstract}

Keyword: Induction heating, petrol, required temperature, power JGBT transistors

Received: November 27, 2020. Revised: March 1, 2021. Accepted: March 26, 2021. Published: April 17, 2021.

\section{Introduction}

According to the Committee of the State Duma of Russia on Energy, Transport and Communications, more than $70 \%$ of the reserves of oil companies are in the range of low rates, that is, on the verge of profitability [1]. The share of hard-to-recover reserves reached $55-60 \%$ and continues to increase. If 15 years ago $55 \%$ of wells produced up to 25 tons of oil per day, today only about 10 tons are produced. Water cut is increasing (the amount of water pumped into the oil reservoir to increase pressure). The same situation is in Kazakhstan.

To increase oil production, it is necessary to heat the oil. This is a multifaceted and serious problem for many oil companies. Different heat carriers are used for heating: steam, hot water, hot gases and oil products, electric energy.
The greatest application is water vapor, which has the highest heat content and heat transfer, is simply transportable and does not pose a fire hazard. They use saturated steam with a pressure of $0.3-0.4 \mathrm{MPa}$, providing oil heating to $80-100^{\circ}$ C.

To heat the oil, electric heating devices are used, which differ in compactness, ease of maintenance and benefit when cheap electricity is available.

The goal of the research is to heat the oil to the required temperature, with the most efficient use of the consumed electricity, without the use of an open flame (furnace, burner), without thermal electric heaters (TENs), and without the use of heat exchangers, the efficiency of which does not exceed $60-80 \%$. This is possible using the induction heating method. [2] 
Induction heating is used to heat technological equipment (oil pipelines, pipelines, tanks, etc.), heat liquid media, and dry coatings of materials (for example, wood). The most important parameter of induction heating settings is frequency.

For each process, there is an optimal frequency range that provides the best technological and economic results. For induction heating, frequencies from $50 \mathrm{~Hz}$ to $5 \mathrm{MHz}$ are used.

The advantages of induction heating:

Electric energy is transferred directly to the heated body and allows direct heating of materials, with an increase in the heating rate. [3]

1. The transfer of electrical energy directly to the heated body occurs in a non-contact manner. This is convenient in conditions of regulating the heating temperature and for automating the heating process.

2. Due to the phenomenon of the surface effect, maximum power is released on the surface layer of the heated product. Therefore, induction heating provides fast heating of the product and is more economical than other methods of heating oil.

3. Induction heating in most cases makes it possible to reduce the overall dimensions of the heated material at high current frequencies.

Oil heating is a multifaceted and serious problem for many oil companies. Oil heating is carried out under various conditions and for various purposes: during oil transportation, in front of metering stations, during winter operation of lowproduction wells and in some other cases [1]. Different heat carriers are used for heating: steam, hot water, hot gases and oil products, electric energy. Water vapor has the greatest application, possessing the highest heat content and heat transfer, it is simply transportable and does not represent a fire hazard. They use saturated steam with a pressure of $0.3-0.4 \mathrm{MPa}$, providing oil heating to $80-100^{\circ} \mathrm{C}$.

Heating oil in oil pipelines to the required temperature, with the most efficient use of the energy expended, is possible using the induction heating method.

\section{Literature review}

Induction heating is used to heat technological equipment (oil pipelines, pipelines, tanks, etc.), heat liquid media, dry coatings, and materials (for example, wood) [4]. The most important parameter of induction heating settings is frequency. For each process, there is an optimal frequency range that provides the best technological and economic indicators. For induction heating, frequencies from $50 \mathrm{~Hz}$ to 5 $\mathrm{MHz}$ are used.

The aim of the research is to develop a frequency converter on JGBT transistor modules for induction heating of oil in oil pipelines with a high efficiency index. The fact is that the main losses of electricity occur in power JGBT transistors, if there are few power transistors, then there will be few losses, and accordingly, the frequency converter will have high efficiency values. This will lead to a high value of the efficiency of the frequency converter and energy saving, as well as to lower cost [5].

In article [6], the introduction of a microprocessor inverter control system allows you to control the thermal operation of the frequency converter. Moreover, the design is simpler and more technologically advanced for manufacturing, and they can be manufactured, assembled and tested at the enterprises of Kazakhstan. In addition, the developed technology and design methods allows you to create an individual induction heater for a specific process.

In the article [7], transistor frequency converters of induction heating will use SKYPER 52 drivers, the task of which is to convert a lowcurrent logic signal of the controller into a gate control signal, the power of which should be sufficient for quick recharging of IGBT shutter capacities. Since power switches operate at voltages significantly exceeding the potentials of the controller signals, the gate control device must carry out a high-voltage level shift or galvanic isolation of control pulses and pulses arriving at the gates. In addition, the modern SKYPER 52 drivers contain numerous protective and service functions necessary for IGBT uptime in all operating modes, including emergency ones.

In the article $[8,9]$ the application of certain methods of calculation and analysis of converting devices is connected with the consideration of specific schemes. Taking into account the specific features of a particular converter and the mathematical model chosen for its description is the basis for the development of the most effective calculation and analysis methods in this case.

\subsection{Purpose of the study}

The advantages of induction heating.

1. It is possible to heat oil in oil pipelines without violating the technological process of oil transportation, while the heating speed increases.

2. The induction method of heating oil in oil pipelines allows you to control the heating 
temperature, power and other parameters, as well as beneficial when cheap electricity is available.

3. Due to the phenomenon of the surface effect, the maximum power is released in the surface of the pipeline, while it is more economical in comparison with other methods of heating oil.

\subsection{Models and methods}

This method of heating oil in oil wells is used in Latin America. As a review and analysis of the literature, as well as technical documentation shows, the unit cost of existing foreign designs of heaters is very high.

In this regard, the introduction of foreignmade heaters in Kazakhstan is unprofitable, since the payback period reaches about ten years. Therefore, you should develop your own induction heaters based on your own developments, which will be cost-effective.

Given that at a low cost of electricity compared to the cost of electricity abroad, as well as a decrease in the unit cost of the entire installation, the development and implementation of induction heaters is an urgent problem. The article proposes an induction heater and a frequency converter on JGBT transistor modules. Moreover, the design is simpler and more technologically advanced for manufacturing, and they can be manufactured, assembled and tested at enterprises in Kazakhstan.

In addition, the developed technology and design methods allow you to create an individual induction heater for a specific type of oil heating process.

Modern induction heaters are classified according to the range of operating frequencies, which determine the scope of induction installations.

The principle of operation of induction heaters is simple. If a metal work piece or parts are placed in an alternating magnetic field, then, according to the law of electromagnetic induction, an electromotive force is induced in it, under the influence of which an alternating electric eddy current will flow.

This current will heat the body of this work piece or part to the required temperature. This current will heat the body of this work piece or part to the required temperature. The general concept of the article is that with the help of an induction heater it is possible to heat oil in oil wells, and thus, increase oil production in low flow wells, that is, increase the profitability of oil production.

To do this, it will be necessary to develop various designs of the induction heater and frequency converter on JGBT transistor modules. The induction heater will be located at the bottom of the oil well and must be leak proof as well as corrosion resistant. As a rule, a frequency converter consists of a rectifier and an inverter. The rectifier will be connected to a three-phase $\mathrm{AC}$ voltage source and will be located on the surface of the earth, and the inverter at the bottom of the oil well with an induction heater.

This simplifies the method of supplying electricity to the bottom of the oil well, since the electricity from the rectifier is supplied by DC voltage. Calculations showed that the overall dimensions of the JGBT transistors and transistor modules can be placed at the bottom of the oil well with oil pipes with a diameter of $150-200$ $\mathrm{mm}$.

The design of the induction heater, which will be located at the bottom of the oil well, is a metal pipe. The main purpose of the induction heater is to create an electromagnetic field of any configuration in order to create eddy currents in the heater core.n general, an induction heater is an energy converter that converts electricity to heat [2].

Test results and discussion. If an induction heater is considered as an electric machine converter with a braked rotor, then it will convert electric energy into thermal energy [2].

In this case, the heater will have basic main dimensions: the outer diameter D1 and the inner diameter D2, the estimated length $\mathrm{L}$, the base power $\mathrm{P}_{\mathrm{b}}$, frequency $\mathrm{f}$. The sizes $\mathrm{D} 1, \mathrm{D} 2$ and $\mathrm{L}$ are related to power, frequency $\mathrm{f}$ and electromagnetic loads following expression [2]

$\frac{D^{2} \cdot L \cdot f}{P_{b}}=\frac{6.1 \cdot 10^{11}}{k_{B} K_{O} A \cdot B}$

where: A- is the linear load of the heater, B- is the induction in the core of the heater, $\mathrm{k}_{\mathrm{B}}=1.1$ is the coefficient of the shape of the voltage curve, $\mathrm{k}_{\mathrm{o \sigma}}=$ 0.95 is the winding coefficient.

The base power of an induction heater is

$$
P b=P_{n} \frac{k_{E}}{\eta \cdot \cos \varphi}
$$


where $\mathrm{Pn}$ - is the rated power of the induction heater, $\mathrm{kW} ; \mathrm{k}_{\mathrm{E}}$ - the ratio of the EMF of the heater winding to the nominal voltage, which can be approximately determined from $=0.93-0.98$. [1]. The values of efficiency $\eta=0.88$ and power factor $\cos \varphi=0.85$ can be taken according to [1]. Then the rated current is

$$
\begin{gathered}
I_{1 n}=\frac{P_{n}}{U_{1} \cdot \eta \cdot \cos \varphi}=\frac{25000}{514 \cdot 0.88 \cdot 0.85} \\
=65 \mathrm{~A}
\end{gathered}
$$

where $\mathrm{U}_{1}=514 \mathrm{~V}$ is the rated voltage of the induction heater.

The preliminary selection of electromagnetic loads A, B, must be carried out very carefully, since they determine not only the calculated length of the heater, but also, to a large extent, the characteristics of the heater. When choosing specific values of $\mathrm{A}$ and $\mathrm{B}$ from practice, they are guided by the following data: $\mathrm{A}$ $=300 \mathrm{~A} / \mathrm{cm}$ and $\mathrm{B}=8,000$. Gs $=0.8 \mathrm{Tc}$.

Then from the expression (1) for a given value of the outer diameter the heater

$\mathrm{D} 1=150 \mathrm{~mm}$ can determine the length of

$$
L=\frac{6.1 \cdot 10^{11} \cdot P_{B}}{k_{B} k_{o} \cdot A \cdot B \cdot D^{2} \cdot f}
$$

For a given rated power $\mathrm{Pn}=25 \mathrm{~kW}$ and frequencies $\mathrm{f}=2000 \mathrm{~Hz}$, also with the above values of efficiency $\eta=0.88$, power factor $\cos \varphi=$ 0.85 and $k_{E}=0.95$, the base power will be equal to

$$
P_{b}=P_{n} \frac{k_{E}}{\eta \cdot \cos \varphi}=25 \cdot \frac{0.95}{0.88 \cdot 0.85}=31.7 \mathrm{~kW}
$$
be equal to

In this case, the length of the heater will

$$
\begin{aligned}
L= & \frac{6.1 \cdot 10^{11} \cdot 31.78}{1.1 \cdot 0.95 \cdot 300 \cdot 8000 \cdot 15^{2}} \cdot 200 \\
& =17.17 \mathrm{sm}
\end{aligned}
$$

Preliminary calculations show that an induction heater with a rated power of $\mathrm{PH}_{\mathrm{H}}=25$ $\mathrm{kW}$, an outer diameter of $\mathrm{D} 1=150 \mathrm{~mm}$, a length of $\mathrm{L}=171.7 \mathrm{~mm}$ at a frequency of $\mathrm{f}=2000 \mathrm{~Hz}$ can be freely placed at the bottom of the oil well.

\begin{tabular}{|c|c|c|c|c|c|}
\hline $\begin{array}{l}\text { Current } \\
\text { Frequenc } \\
\text { y (f), Hz }\end{array}$ & 50 & 500 & 1000 & 1500 & 2000 \\
\hline $\begin{array}{l}\text { Length of } \\
\text { induction } \\
\text { heater L, } \\
\mathrm{cm}\end{array}$ & $\begin{array}{l}686 \\
, 8\end{array}$ & $\begin{array}{l}68, \\
68\end{array}$ & $\begin{array}{l}34,3 \\
4\end{array}$ & $\begin{array}{l}22,8 \\
9\end{array}$ & $\begin{array}{l}17,1 \\
7\end{array}$ \\
\hline
\end{tabular}
Naturally, at other frequencies these sizes will be different.
Table 1 presents the dependence of the length $\mathrm{L}$ of the induction heater on the frequency $\mathrm{f}$ for a given outer diameter D1 $=150 \mathrm{~mm}$.

When designing an induction heater, it is necessary to take into account the quality of heating, i.e. creating the desired temperature distribution in the heater body and achieving the highest efficiency value, as well as take into account special technological and other requirements in terms of geometric dimensions, materials used, etc.

A variety of heating systems, a limited range of weight and size parameters and the specificity of the oil heating process lead to the fact that the design of the induction heater is very diverse. Designing a workable induction heater with minimum weight and size parameters that increases the efficiency and power factor is not an easy task.

The duration of induction heating of the heater is associated with a number of factors. From the point of view of productivity and installation efficiency, the heating time should be as short as possible. However, with very fast heating, a significant temperature difference is obtained between the surface and the center of the heater billet.

The calculation of the induction heater consists in choosing the current frequency, determining the heating time, calculating the dimensions (diameter and length) of the heater, determining the required power of the frequency converter and the capacitance of the capacitor.

The initial data are the material and sizes of the heater, as well as the heating time.The mass of the induction heater is determined as follows

$$
G=\rho_{m} \cdot \pi \cdot\left(R_{1}^{2}-R_{2}^{2}\right) \cdot L
$$

where $\rho_{\mathrm{m}}=7880 \mathrm{~kg} / \mathrm{m}^{3}$ - is the specific gravity of the metal, $\mathrm{R}_{1}$ and $\mathrm{R}_{2}$ are the outer and inner radii of the heater, in $\mathrm{m}$; $\mathrm{L}$ is the length of the heater, in $\mathrm{m}$.

With the above parameters, the mass of the heater will be equal to 


$$
G=7880 \cdot 3,14 \cdot\left(0,15^{2}-0,075^{2}\right) \cdot 0,1717=71,69 \mathrm{~kg}
$$

At a given heating temperature, in degrees $\mathrm{C}$, the required rated power for heating the induction heater is determined by the following expression, according to [3].

$$
P_{N}=\frac{c_{0}^{1200} \cdot t_{\text {load }} \cdot G}{\tau_{\text {load }}} . k W
$$

where $c_{0}^{1200}$ - the average heat capacity of steel is $0.704 \mathrm{~kJ} / \mathrm{kg}$. hail.

From the last expressions, it is possible to determine the heating $\tau_{\text {load }}$ time in seconds at a given heating temperature $\tau_{\text {нагр }}$

$$
\tau_{\text {load }}=\frac{c_{0}^{1200} t_{\text {load }} \cdot G}{P_{n}}
$$

Taking into account the above data and at a given heating temperature tnag $=3000 \mathrm{C}$, the heating time $\tau_{\text {нагр }}$ will be equal to

$$
\tau_{\text {нагр }}=\frac{0,704 \cdot 300 \cdot 71,69}{25,0}=605,6 c=10,1 \mathrm{~min}
$$

It turns out the actual heating time of the induction heater is 10.1 minutes.

Table 2 presents the dependence of the heating time of the induction heater on frequency.

\begin{tabular}{|l|l|l|l|l|l|}
\hline $\begin{array}{l}\text { Induction } \\
\text { heater } \\
\text { heating } \\
\text { time, } \\
\text { min. }\end{array}$ & 403,8 & 40,38 & 20,2 & $\begin{array}{l}13, \\
5\end{array}$ & 10,1 \\
\hline $\begin{array}{l}\text { Current } \\
\text { Frequenc } \\
\text { y } \\
(t), \mathrm{Hz}\end{array}$ & 50 & 500 & 1000 & $\begin{array}{l}150 \\
0\end{array}$ & 2000 \\
\hline
\end{tabular}

When induction heating of metal billets, the frequency is selected based on the maximum efficiency [3]. In this case, the current frequency must be selected based on the optimal weight and dimensions of the induction heater and the heating time. As can be seen from tables 1 and 2, the industrial frequency of $50 \mathrm{~Hz}$ is not suitable, since the induction heater will have a length of 6.87 meters and a heating time of 403.8 minutes or 6.73 hours.

The optimal frequency is $1000-1500 \mathrm{~Hz}$, while the length of the induction heater is 34.34 $22.89 \mathrm{~cm}$ and the heating time is $20.2-13.5$ minutes. Such a frequency is acceptable for switching transistors.

Transistor frequency converters of induction units consist of a rectifier and an inverter [7]. The technology for creating a rectifier on diodes and thyristors is known and well developed. Of interest is an inverter that will be implemented on transistor JGBT modules.

In most cases, the frequency converter runs on four transistors. In this case, it can be performed on two transistors. This idea was patented in the intellectual property committee of the Republic of Kazakhstan. [5]. Two transistors can be successfully placed at the bottom of the oil well. It should be noted that the main losses of electricity occur in transistors and with a decrease in half, respectively, increases the efficiency of the frequency converter.

Induction heating of the oil pipeline occurs as follows, if an alternating high-frequency current is passed through the windings of the oil pipeline (Fig. 1), an alternating magnetic field is formed, which intersects the metal walls of the oil pipeline and induces eddy currents in them. These currents heat the metal walls of the pipeline to the desired temperature and, accordingly, oil.

The frequency converter contains two three-phase rectifiers, two keys on transistors, a high-frequency transformer with two primary and one secondary windings and an oil pipeline with an inductor (Fig. 1).

An alternating three-phase voltage is supplied to the input of the frequency converter, which is converted by two three-phase rectifiers into two constant voltage sources, one has a direct polarity and the other has a reverse polarity. These two DC voltage sources are connected counter-to each other (Fig. 1).

The three-phase rectifier 1 is connected to the first primary winding $\mathrm{W} 1$ of the highfrequency transformer through the first transistor switch T1, and the second three-phase rectifier 2 is connected to the second primary winding $\mathrm{W} 2$ of the high-frequency transformer through the second transistor switch $\mathrm{T} 2$, and the secondary winding W3 of the transformer is connected to the inductor $\mathrm{W}$ of the oil pipeline, and the three-phase rectifiers are powered by a three-phase power source. 


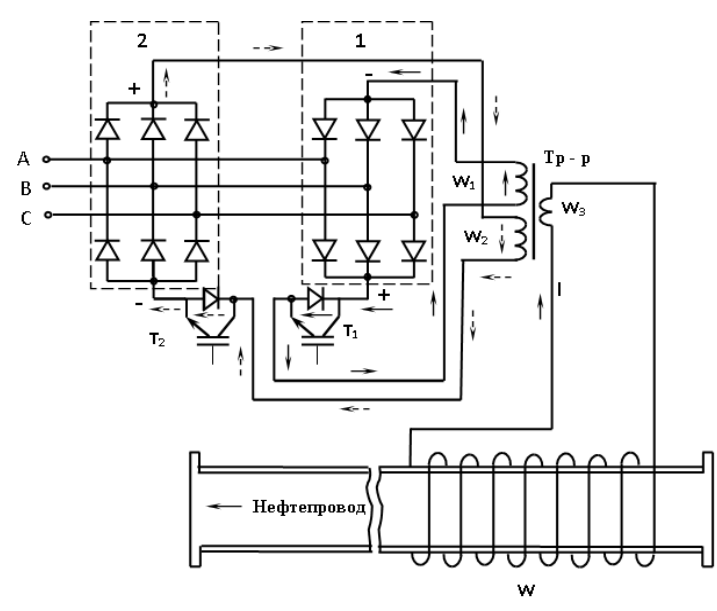

Fig. 1: DC voltage sources are connected counterto each other

Three-phase rectifiers converts a three-phase voltage to a constant voltage, and transistor switches $\mathrm{T} 1$ and $\mathrm{T} 2$ converts a constant voltage into an alternating single-phase voltage of the required frequency fn (Fig. 2). The transformer lowers the alternating voltage of high frequency to the required value. The secondary winding of the transformer is connected to the inverter of the pipeline.

When the transistor switch $\mathrm{T} 1$ is turned on, the constant voltage of the three-phase rectifier 1 is connected to the first primary winding W1 of the high-frequency transformer and current will flow through the winding W1 until time t1 (Fig. 2). Thus, a positive half-wave of the input voltage of the primary winding W1 of the high-frequency transformer is formed (the current direction is indicated by a solid arrow).

At time $\mathrm{t} 1$, the transistor switch $\mathrm{T} 1$ is turned off, and the transistor switch T2 is turned on. In this case, the constant voltage of the threephase rectifier 2 is connected to the second primary winding W2 of the high-frequency transformer and the reverse polarity current will flow through the winding W2 until time t2 (Figure 2 ). Thus, a negative half-wave of the input voltage of the primary winding W2 of a high-frequency transformer is formed (the current direction is indicated by a dashed arrow).

The frequency voltage of the frequency converter for induction heating of the oil pipeline is determined by the known expression

$$
\mathbf{f}_{\Pi}=\frac{1}{T}
$$

where $\mathrm{T}$ - is the voltage period of the frequency converter.

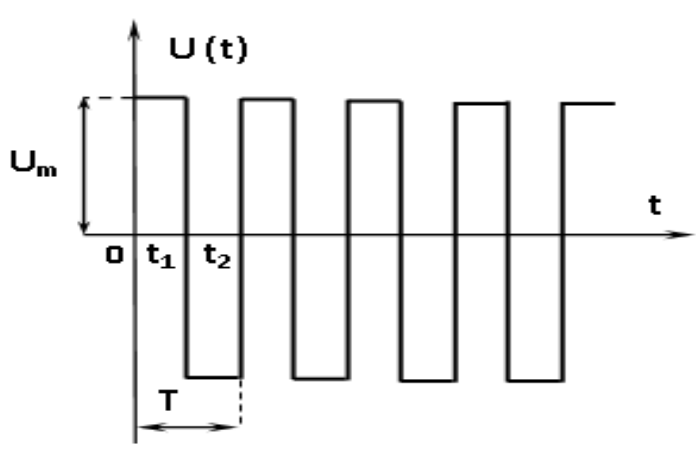

Fig.2: T1 and T2 converts a constant voltage into an alternating single-phase voltage of the required frequency fn

High-frequency voltage, the overall dimensions of the high-frequency transformer are reduced, so the frequency converter will have low overall dimensions.

\section{Computational experiment}

A prototype frequency converter was designed and manufactured. Figure 4 shows a prototype of a $6 \mathrm{~kW}$ frequency converter for frequencies from 2 to $20 \mathrm{kHz}$. The frequency converter is implemented on IGBT transistors. Induction heating of metal was used as a load for the frequency converter.

The inverter, made on transistor JGBT modules, is controlled by control drivers [7]. The term "driver" refers to a chip or module on a printed circuit Board that controls a semiconductor power module or a discrete semiconductor device (MOSFET, IGBT, bipolar transistor, thyristor, etc.) that performs protective and service functions, Fig. 3

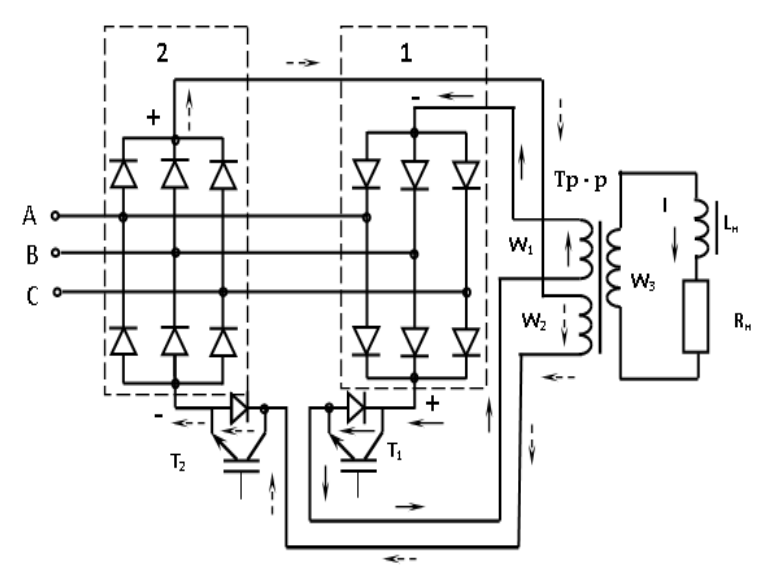

Fig. 3: transistor JGBT modules, is controlled by control drivers 


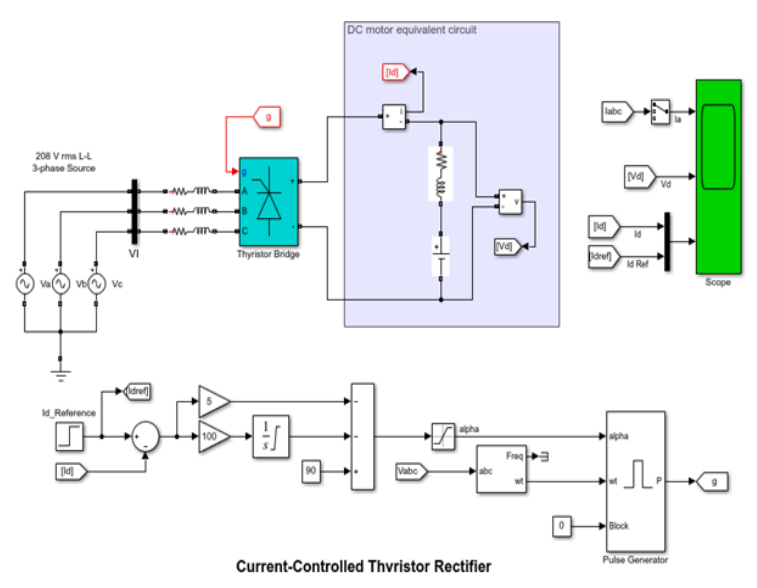

Fig.4: require some power to turn on and off

The main task solved by the control scheme is to coordinate the pulse levels generated by the controller (microprocessor) with the control signals of the power key inputs, which require some power to turn on and off, Fig. 4

\subsection{Discussion and prospects for further research}

The results of an experimental study showed that an experienced sample of the frequency converter works stably, gives the specified technical characteristics. Figure 4 shows the process of induction surface heating of a metal with a diameter of $120 \mathrm{~mm}$ at a frequency of $20 \mathrm{kHz}$. This is done in order to show that the frequency converter heats only the metal surface at a frequency of $20 \mathrm{kHz}$, while the heating temperature reaches 800 degrees.

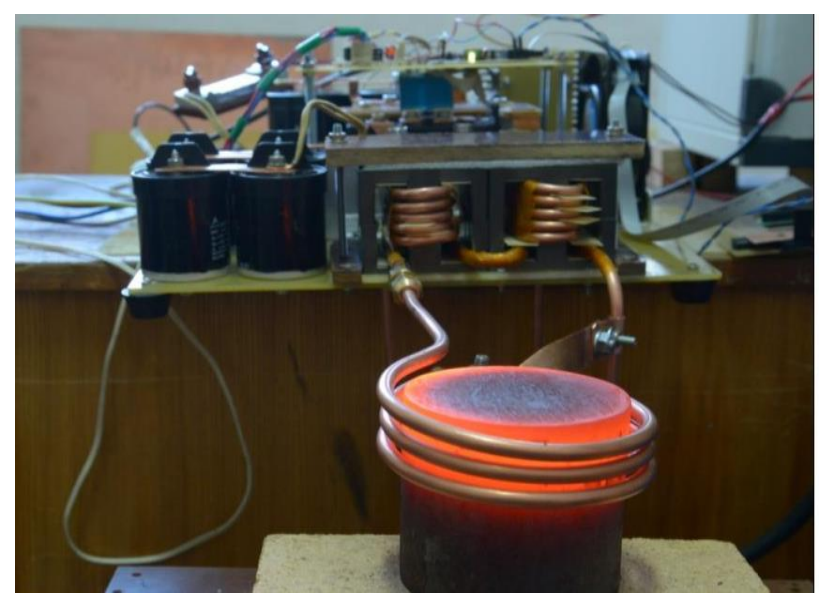

Fig. 5: The process of induction surface heating of metal with a diameter of $120 \mathrm{~mm}$ at a frequency of $20 \mathrm{kHz}$.

\section{Acknowledgments}

The frequency converter, made on two transistors, will have less electrical losses and, accordingly, this will lead to an increase in efficiency, compared with a similar frequency converter and lower cost.

MITSUBISHI's VIPM Series Intelligent Power Modules (IPM), which is a new stage in the development of power switches based on IGBT modules and is a functionally complete product made in a compact insulated case, is currently developed and launched on the market.

Figure 3 shows the IGBT transistor module of MITSUBISHI, operational characteristics. As can be seen from table 1, these transistors are designed for high voltages, currents and powers, and the frequency converter, made on these transistor modules, allows heating large oil pipelines.

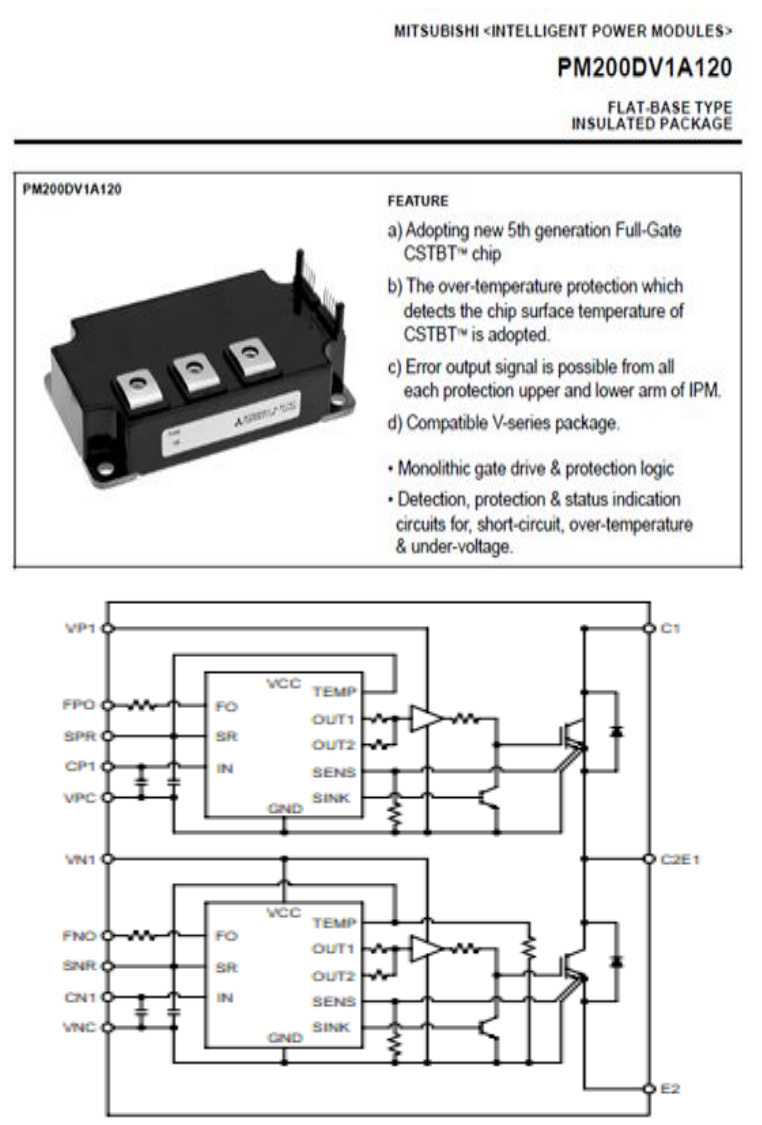

Fig.6: MITSUBISHI PM200DV1A120 transistor IGBT module with built-in control driver and switching circuit

\section{Conclusion}

In electrical systems, including those with electric energy converters, there are those for which the subsequent values of the output variable do not depend on the way the system reaches its present state. 
Such systems are called state-determined systems. The analysis of these systems can be performed by the method of alternating states.

The developed training layout allows you to:

- to master the skills of designing and implementing a frequency converter on JGBT transistor modules with single-phase power;

- understand at an affordable level the basics of using microcontrollers and microprocessor control systems in railway transport;

- implement a control algorithm for a frequency converter with an induction heater;

- develop a methodology for the selection and design of the converter

-frequencies on JGBT transistor modules for induction heating of metal

- skills of installation work.

\section{References:}

[1] Isembergenov N.T., Baykenov A.S., Sagyndikova A.Zh .. "Automatic control of leakage of uncontrolled sections of gas pipelines", Doklady / Bayandamalary. National Academy of Sciences of the Republic of Kazakhstan. No. 5/2010, pp. 87-89 Almaty.

[2] Isembergenov NT, Sagyndykova A. Zh., A.M. Nauhan Transistor frequency converter for induction heating of metal. Reports of NAS RK, Almaty, No. 1, 2014 C 118-122, ISSN 2518-1483 (Online), ISSN 2224-5227 (Print)

[3] Isembergenov N.T. A frequency converter for induction heating of an oil pipeline with threephase power. Patent number 99534. Copyright certificate for an innovative patent. Intellectual Property Rights Committee of the Ministry of Justice of the Republic of Kazakhstan, Bull. No 18 on $09 / 29.2017$

[4] Vladimirov V.S. Equations of mathematical physics. M : Nauka, 1988.

[5]Lysakov A.A. Electrotechnology: Lecture course, study guide. - Stavropol, World, 2013.$124 \mathrm{~s}$

[6] Fogel, A.A., Induction Method for Holding Liquid Metals in Suspension, Leningrad: Mechanical Engineering, 1989. 79 p.

[7] Mitkov A. Theory of experiment.-Ruse.: Dunav pres, 2011.227s.

[8] Systems of automation and telemechanics on the railways of the world. Textbook for high schools. Transport / Trans. from English; under the editorship of G. Teega, S. Vlasenko. - M .: Intext, 2010.

[9] Solnitsev R.I. Automation of design of automatic control systems. - M.: Higher School, 1991.
[10] Kuzina I.V., Zhdanov V.S., Denisova T.S., Vaganova M.Yu. Software for CAD of elements and automation systems: Text of lectures. - M.: MIEM, 1990.

[11] Kosarev V.P., Surkov E.M., Bakova I.V. Technical equipment ACS. - M.: Finance and Statistics, 1986.

[12] Armensky E.V., Ivanko A.F., Falk G.B. The influence of manufacturing accuracy on the sensitivity of electromechanical devices. // Standards, measuring equipment. - 1980. - No. 3.

[13] V. Y. Gorfinkel, V. A. Shvandara "Enterprise Economics" Moscow 2000.

\section{Creative Commons Attribution License 4.0 (Attribution 4.0 International, CC BY 4.0)}

This article is published under the terms of the Creative Commons Attribution License 4.0

https://creativecommons.org/licenses/by/4.0/deed.en_US 